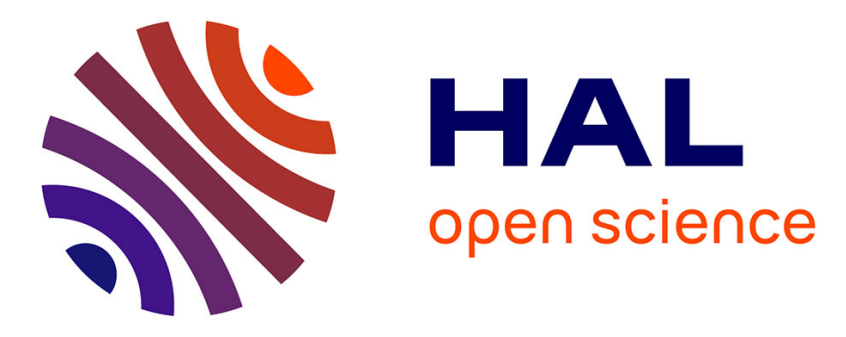

\title{
Effect of nitriding/nanostructuration of few layer graphene supported iron -based particles; catalyst in graphene etching and carbon nanofilaments growth
}

Walid Baaziz, Georgian Melinte, Ovidiu Ersen, Cuong Pham-Huu, Izabela Janowska

\section{To cite this version:}

Walid Baaziz, Georgian Melinte, Ovidiu Ersen, Cuong Pham-Huu, Izabela Janowska. Effect of nitriding/nanostructuration of few layer graphene supported iron -based particles; catalyst in graphene etching and carbon nanofilaments growth. Physical Chemistry Chemical Physics, 2014, 16 (30), pp.15988. 10.1039/C4CP01887G . hal-03518102

\author{
HAL Id: hal-03518102 \\ https://hal.science/hal-03518102
}

Submitted on 9 Jan 2022

HAL is a multi-disciplinary open access archive for the deposit and dissemination of scientific research documents, whether they are published or not. The documents may come from teaching and research institutions in France or abroad, or from public or private research centers.
L'archive ouverte pluridisciplinaire HAL, est destinée au dépôt et à la diffusion de documents scientifiques de niveau recherche, publiés ou non, émanant des établissements d'enseignement et de recherche français ou étrangers, des laboratoires publics ou privés. 


\title{
Effect of nitriding/nanostructuration of few layer graphene supported iron - based particles; catalyst in graphene etching and carbon nanofilaments growth.
}

\author{
Walid Baaziz, ${ }^{\mathrm{a}}$ Georgian Melinte, ${ }^{\mathrm{b}}$ Ovidiu Ersen, ${ }^{\mathrm{b}}$ Cuong Pham-Huu, ${ }^{\mathrm{a}}$ and Izabela Janowska ${ }^{*, a}$ \\ ${ }^{a}$ Institut de Chimie et Procédés pour l'Energie, l'Environnement et la Santé (ICPEES), UMR 7515 \\ CNRS, Université de Strasbourg, ECPM, France, Tel/Fax : +33 (0) 3688526 33/+ 33 (0) 3688526 \\ 74 \\ *E-mail :janowskai@unistra.fr \\ ${ }^{b}$ Institut de Physique et Chimie des Matériaux de Strasbourg (IPCMS), UMR 1504 CNRS, France
}

Stable, highly faceted and dispersed iron nitride particles supported on few layer graphene are obtained by ammonia decomposition on iron-based particles at the temperature commonly used for the synthesis of N-doped CNTs and graphene etching. The TEM/EELS analysis reveals nitrogen diffusion in a bulk of the particles. The resulted facet $\mathrm{FeN}_{\mathrm{x}}$ catalyst exhibits high activity in the etching of graphene, which is assisted by catalyst reorganization. The ammonia decomposition is used for the first time for graphene etching, while the highly facet catalyst has an impact on the etched channels structures. According to the shape of the active planes of the catalyst, the etching results in sharp "V" channels' ends and often "step-like" edges. The $\mathrm{FeN}_{\mathrm{x}}$ morphology proves previously reported triangularisation of arches in highly doped by $\mathrm{N}$ carbon nanotubes. The conditioning of the catalyst by its shaping and nitrogen incorporation is investigated additionally in the carbon nanostructures formation, for decomposition of ethane. The herringbond CNFs, "hollow" bamboo-like CNFs/CNTs or CNTs are observed effectively.

\section{Introduction}

Design of carbon nanostructures (CNTs, CNFs, graphene) with specific chemical/physical properties in view of particular applications is of high interest. Since the CCVD method allows high yield synthesis of carbon nanostructures, a tailoring of the final structures by controlling the operating conditions constitutes a large area of research, due to the impact of many parameters such as catalyst, support, carbon precursor... ${ }^{1-3}$ In general, $\mathrm{Ni}$ is considered as an efficient catalyst for CNFs production, while $\mathrm{Fe}$ is for CNTs formation. ${ }^{4}$ However even for a given metal the family of CNFs and CNTs is large and diverse as long as shape and diameter of catalyst vary. This is related to different local kinetics of carbon diffusion/precipitation and orientation of formed carbon layers - parallel to the metal catalyst surface. ${ }^{5,6}$ The round shape, graphite supported Ni catalyst particles lead to CNTs, whereas the sharp edges ones to fishbone CNFs formation. ${ }^{7}$ A desirable structural conditioning of catalyst remains difficult to achieve, control and observe due to the particles' easy shape reconstruction. ${ }^{8,9}$

On the other hand, a chemical doping of CNTs with heteroatoms, such as N, results in bamboo-like structure; ${ }^{3,10}$ where for high $\mathrm{N}$ content, the orientation of graphitic walls is closed to the "fishbone" $\mathrm{CNFs}^{11}$ and arches reveal triangular cross-section ${ }^{12}$ - suggesting the presence of faceted catalyst. Ndoped CNTs demonstrate high performance particularly in catalysis. ${ }^{13-16}$ The most common way to 
synthesize nanostructures with $\mathrm{N}$ incorporated into the carbon matrix is "in-situ" doping/CVD growth on Fe with ammonia as nitrogen precursor. ${ }^{17-19}$ It involves ammonia decomposition ${ }^{20}$, which is also an important reaction in energy production; first: by a nitridation ${ }^{21}$-activation of metals (alternative to $\mathrm{Pt}$ in ORR reaction), ${ }^{22-26}$ second: for the production of $\mathrm{CO}_{\mathrm{x}}$-free $\mathrm{H}_{2}$ for PEMFCs ${ }^{27-29}$. The nitriding of iron or iron oxides particles aims also at materials with high magnetic performance. ${ }^{30,31}$

High reactivity of $\mathrm{Fe}$ with carbon renders also this metal, together with $\mathrm{Ni}$, a useful catalyst for etching of graphene, allowing access to planar carbon nanostructures with specific properties related to their planarity, defined size and shape (quantum dots, nanorribons). ${ }^{32-34}$

Contrary to the carbon nanofilaments growth, the impact of catalyst shape in the etching of graphene was never investigated.

In the present work we report on the nitridation and faceting of few layer graphene (FLG) supported iron based nanoparticles $\left(\mathrm{Fe}_{3} \mathrm{O}_{4}\right)$ with ammonia at the temperature commonly applied for the etching of graphene and CVD synthesis/ N-doping of carbon nanostructures. The morphology of the treated iron-based particles is investigated by TEM/EELS technique. The impact of the nanostructurisation by faceting/nitrogen incorporation of/into the catalyst is investigated in the etching of graphene; and, by decomposition of ethane, in the growth of carbon nanostructures.

\section{Results and discussion}

\section{Morphology of ammonia treated iron based particles}

The FLG supported spherical $\mathrm{Fe}_{3} \mathrm{O}_{4}$ particles with the average diameter of $(8 \pm 2 \mathrm{~nm})^{35}$, (Fig. 1A), are treated by $\mathrm{NH}_{3} / \mathrm{Ar}$ at $800^{\circ} \mathrm{C}$ for $2 \mathrm{~h}$. Despite high temperature, the treatment results in coalescence of the particles with maximum final size of $50 \mathrm{~nm}$, while an amount of particles remains at their initial size (Fig. 1B, Fig. 5). The etching of FLG is additionally systematically observed (Fig.1B).
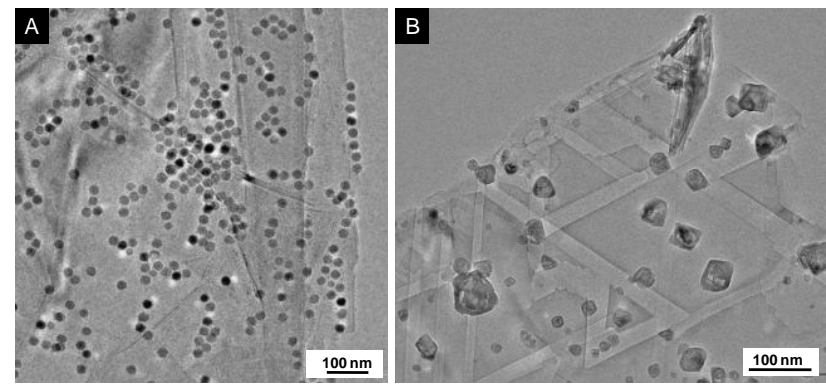

Figure 1. The TEM images of $\mathrm{Fe}_{3} \mathrm{O}_{4} / \mathrm{FLG}$ hybrid before (A) and after ammonia treatment (B).

According to the TEM analysis the overall dispersion of particles remains very high, while the spherical shape of particles changes into the polygonal (hexagonal, rectangular and, punctually triangular) with more or less visible sharp edges. TEM analysis depicts the existence of three main types of particles; i.e. core-shell in majority, homogeneous and semi-core-shell particles located at the edges of graphene (SI). The strong variation in the particles morphology is the result of partial coalescence which depends on localization on the FLG surface, distance between particles, ramping and local temperature. The similar morphology distribution was observed in our previous study for the iron based particles after treatment with hydrogen, although the particles remained spherical. ${ }^{36}$ 
The element mapping performed, by HR-TEM/EELS technique, on the core shell particles of $\sim 50$ and $35 \mathrm{~nm}$, (Fig. 2) reveals that oxygen appears in the same region than iron - suggesting the existence of iron oxide species (Fig. 2A); or only in the shell (Fig.2 B). The detected oxygen can partially or totally originate from the oxygenation once the particle is exposed to air $^{37}$ (highly reductive conditions) and induces observed disorder in the shell structure. The analysis reveal the presence of nitrogen, and contrary to oxygen the nitrogen appears exclusively in the core of particles with average diameter of c.a. 25 and $22 \mathrm{~nm}$, respectively (Fig. 2D).
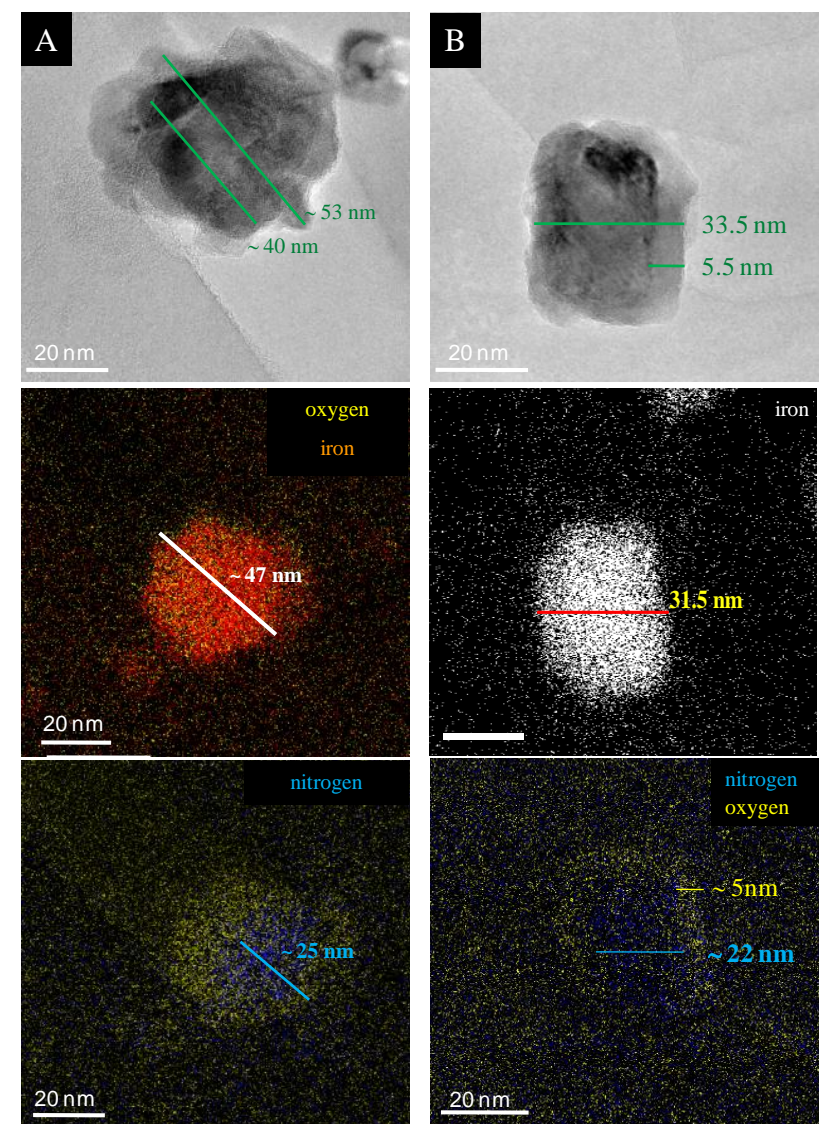

Figure 2. Representative TEM micrographs and elemental mapping (TEM/EELS) of iron base coreshell particles with nitrogen rich core and oxygen contained core-shell (A) or shell (B).

In general, a detection of carbon by TEM/EELS is difficult due to the carbon background from the support, although a very thin carbon layer at the surface can be detected for the core-shell particles suspended over transparent etched channels (Fig. 3). This indicates very low dissolution of carbon in iron particles; carbon which could originate from FLG support or from $\mathrm{CH}_{4}$ formed during the FLG etching. The low dissolution of carbon from FLG is at first linked up with high graphitization degree of FLG.
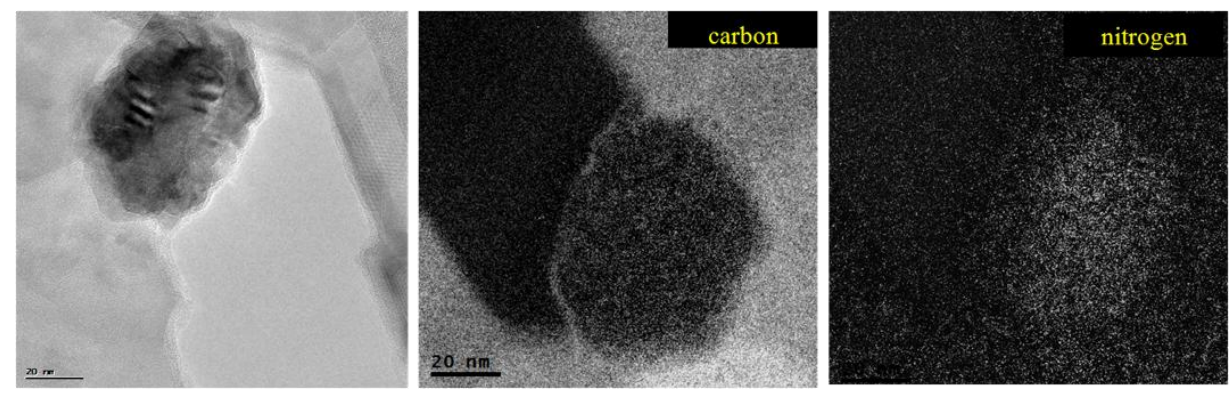
Figure 3. TEM and carbon/nitrogen elements micrographs of core-shell nanoparticle obtained after ammonia treatments.

The second group of particles exhibits highly defined shape with sharp edges and more homogenous redistribution of elements, including nitrogen (Fig. 4). Rarely, these particles exhibit very weak signals from nitrogen (oxygen) which could suggest quasi purely iron composition (Fig.4B). This might be an effect of lower local ammonia concentration; ${ }^{38}$ or the analytical noise insufficiency due to the low nitrogen concentration caused by its high distribution within the particles.
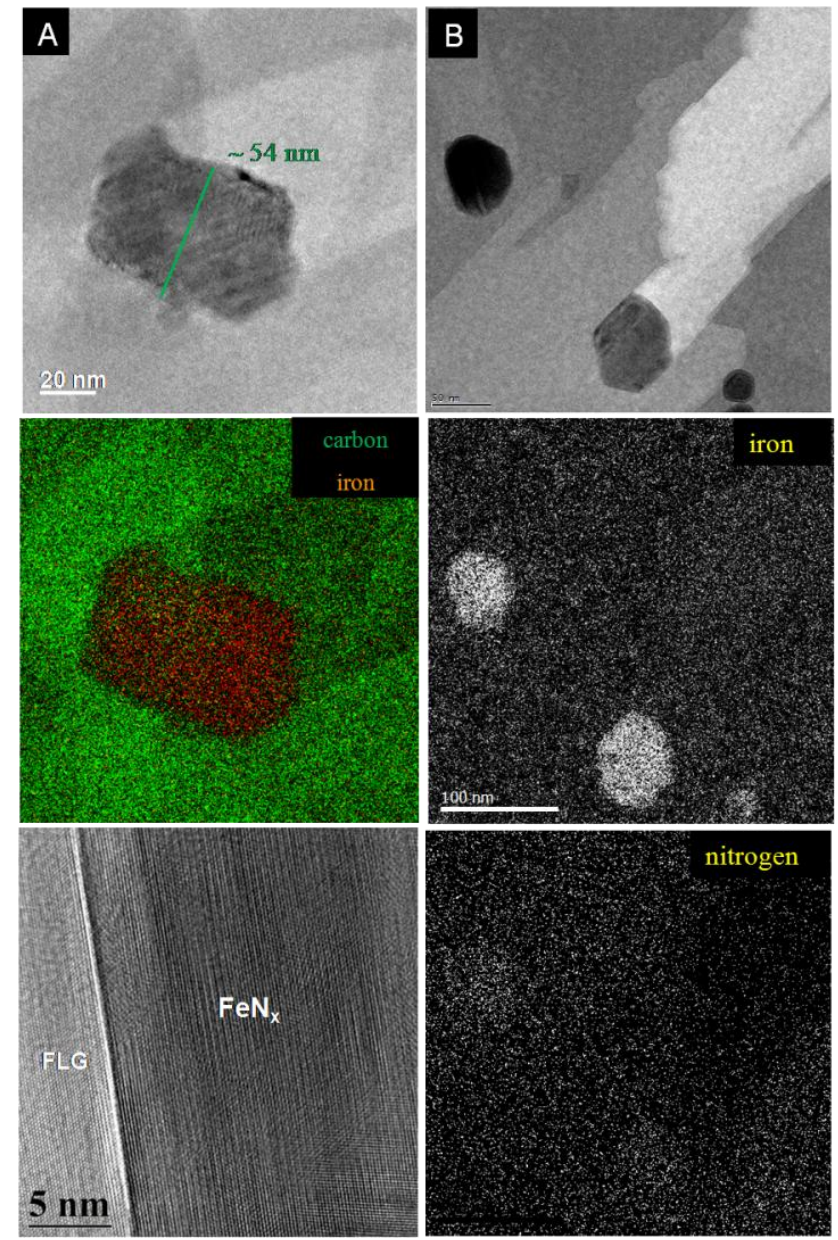

Figure 4. TEM micrographs and $\mathrm{C} / \mathrm{Fe} / \mathrm{N}$ mapping of two homogenous-type particle (A) and (B)

The presence of nitrogen in Fe particles reveals adsorption and bulk diffusion of nitrogen originating from ammonia decomposition:

$$
2 \mathrm{xFe}+2 \mathrm{NH}_{3} \rightarrow 2 \mathrm{Fe}_{\mathrm{x}} \mathrm{N}+3 \mathrm{H}_{2} \uparrow
$$

Since the XRD pattern confirms the formation of $\mathrm{FeN}_{\mathrm{x}}(\mathrm{SI})$, a detailed crystallographic structure will not be defined in this work due to its diversity, which can be related to the existence of different morphology/composition of particles. However, the preliminary data from electron diffraction analysis 
suggest the contribution of $\mathrm{Fe}_{16} \mathrm{~N}_{2}$ (SI), which is in agreement with earlier reported single phase $\alpha$ '$\mathrm{Fe}_{16} \mathrm{~N}_{2}$, observed for ammonia treated spherical core-shell nanoparticles. ${ }^{31}$

The presence or absence of oxygen-rich disordered shells in the formed here particles could be linked to different oxidation potential of nitrides and pure iron, and related formation of passive layer. The oxidation potential of nitrides increases also with a percentage of $\mathrm{N}^{39}$

\section{Stability of $\mathrm{FeN}_{\mathrm{x}} / \mathrm{FLG}$ system}

The shape retransformation of particles, when $\mathrm{NH}_{3} / \mathrm{Ar}$ is switched to Ar during the cooling step, does not happen. Curiously, the spherical like particles can be punctually observed, but the $\mathrm{FeN}_{\mathrm{x}}$ core of particles is highly faceted. Highly stable and well dispersed $\mathrm{FeN}_{\mathrm{x}}$ phase containing particles is a combined effect of nitrogen diffusion, faceting and interaction with support. The additional experiments reveal that the faceting is less pronounced when the particles are treated under $\mathrm{H}_{2} / \mathrm{Ar}$ gas (Fig.5); and in turn, the faceted but highly coalesced big particles are observed when $\mathrm{NH}_{3} / \mathrm{Ar}$ treatment is applied for the particles supported on $\mathrm{Al}_{2} \mathrm{O}_{3}$ (Fig.6).

The relatively high dispersion of the particles treated with ammonia is prevented by faceting of particles, where higher content of atoms is exposed in the basal plane to interact with the support. The additional stabilizing factors are the edges of graphene. Due to the faceting of particles, a dispersion of particles remains quite high over the FLG surface despite a treatment in highly reductive atmosphere $\left(2 \mathrm{~h}\right.$ at $800^{\circ} \mathrm{C}$ ) and etching of the support. Similar stabilization of metal on the FLG support by faceting of particles and the edges of graphene we have observed in our previous study for in-situ TEM heated Pt particles, but only up to $700^{\circ} \mathrm{C} .^{40,41}$
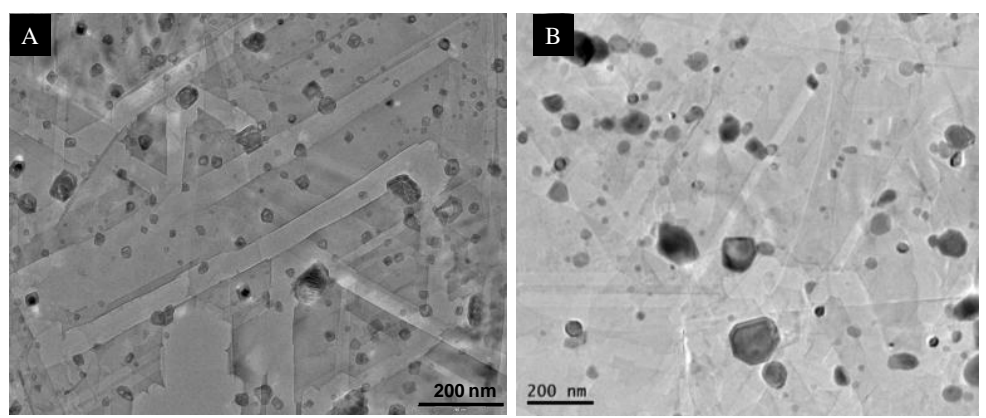

Figure 5. TEM micrographs showing dispersion of $\mathrm{NH}_{3} / \mathrm{Ar}(\mathrm{A})$ and $\mathrm{H}_{2} / \mathrm{Ar}(\mathrm{B})$ treated $\mathrm{Fe}_{3} \mathrm{O}_{4}$ particles supported on FLG.
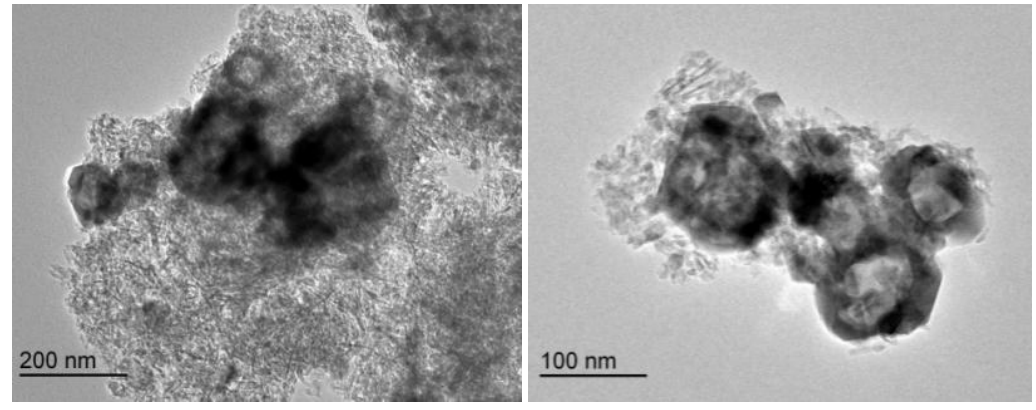

Figure 6. TEM micrographs showing extremely low dispersion of $\mathrm{NH}_{3} / \mathrm{Ar}$ treated $\mathrm{Fe}_{3} \mathrm{O}_{4}$ particles supported on $\mathrm{Al}_{2} \mathrm{O}_{3}$. 


\section{FLG etching}

Apart from nitrogen, a decomposition of ammonia (1) produces hydrogen. The presence of the latter can result into a gasification of carbon to methane (2) and, in the case of highly graphitized carbon support, the etching of support by Fe and the formation of channels in a direction defined by the crystallographic orientation of graphene.

$$
\mathrm{C}_{\text {solid }}+\mathrm{H}_{2} \stackrel{\mathrm{Fe}}{\rightarrow} \mathrm{CH}_{4} \uparrow
$$

Such etching of the FLG support is presently observed. The ammonia decomposition over iron based particles does a nitridation of metal and etches the graphene surface. Here, due to the faceted catalyst, the "ends" of the graphene channels are sharp. The figure 7 presents the carbon maps of the particles described above, i.e. of the core-shell particle from fig. 2A (Fig.7A) and of homogenous particles from Fig. 4A (Fig.7B). It is evident that the shape of etched channels' ends corresponds to the edge shape of the homogenous particles or to the faceted core of core-shell particles with disordered shells. Moreover, the edges" ends of the channels always depict a "V" shape, with apexes localized symmetrically or not (Fig. 7A, B).
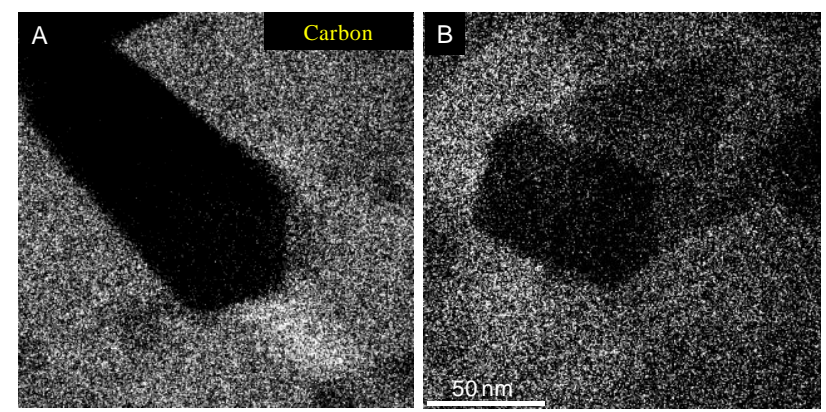

Figure 7. The carbon maps corresponding to the: (A) core-shell particle from fig. 2A and (B) to the homogenous particle from Fig. 4A. "V" shape of etched channels' ends with symmetrically (A) and non-symmetrically localized apex (B).

Statistical TEM/EELS analyses display the highest concentration of nitrogen in the active part of particle: near the "V" ends of channels, which indicates the high catalytic activity of the $\mathrm{FeN}_{\mathrm{x}}$ phase and reorganization of the catalyst with displacement of $\mathrm{FeN}_{\mathrm{x}}$ phase/core (Fig. 2A, SI).

The edges of the etched channels reveal often "steps-like" shape (Fig. 8), however many edges are straight lines as long as the particle does not turn, which suggests the equally active facets of catalyst particle (SI). A direction of cutting, which starts from the graphene edges, follows crystallographic directions of graphene, similarly as it was the case of HOPG etched with Ni nanoparticles (SI) ${ }^{33}$ Fig. 8A features a 2D-projection TEM image of the etched channel by the active core-shell particle with hardly exhibited facets. The 3D mode analysis (Fig. 8B) performed on the same zone at the graphene surface level, in longitudinal xy direction, clearly evidences three sharp edges in the particle.

The observed "step-like" edges shape of channel suggests a 2D rotation and "creep" movement of particle, which may results from competition between the most active facet and the preferential orientation of etching - defined by graphene lattice. The final turning of particles might be caused by 
chemical changes of the graphene surface, e.g. higher local defects concentration. The later is also responsible for the formation of the observed large void in the graphene surface due to the uncontrolled gasification reaction.

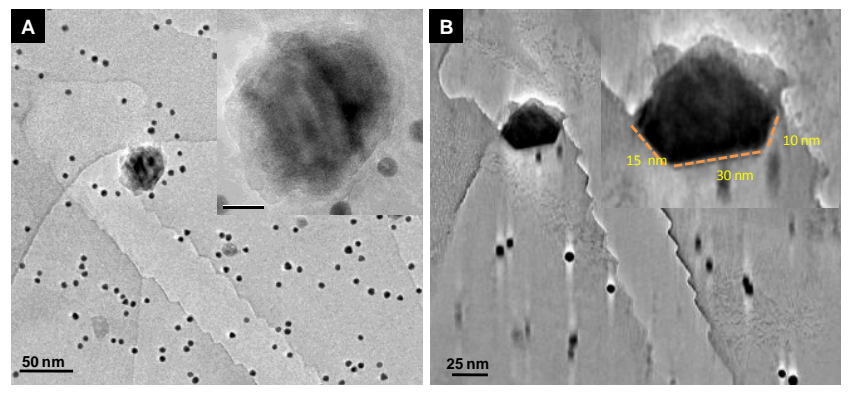

Figure 8. Micrographs of the active in carbon etching, iron nitride particle with hardly exhibited facets by TEM projection (A) and visible facets by longitudinal xy direction at the graphene surface level analysis (B). The step-like edges of channel are visible on the (A, B) micrographs.

\section{Carbon nanofilaments structure}

The sharp edges of $\mathrm{FeN}_{\mathrm{x}}$ catalyst have not only an impact on the structurization of graphene channels. The polygonal and punctually triangle shape of $\mathrm{FeN}_{\mathrm{x}}$ core/particles (SI), observed here, together with the "V" shape of the channels "ends", confirms a contribution of $\mathrm{FeN}_{\mathrm{x}}$ phase in the earlier reported triangularisation of nitrogen rich arches in bamboo-like CNTs. ${ }^{12}$

Presently, the impact of catalyst shape and nitrogen incorporation on the growth of carbon nanofilaments is investigated by performing a decomposition of ethane. A decomposition of the hydrocarbon is preluded by faceting (and reduction) step of the FLG supported $\mathrm{Fe}_{3} \mathrm{O}_{4}$ with $\mathrm{H}_{2} / \mathrm{Ar}$, at first, and $\mathrm{NH}_{3} / \mathrm{Ar}$ in the second experiment.

The $\mathrm{C}_{2} \mathrm{H}_{6}$ decomposition on the $\mathrm{H}_{2} / \mathrm{Ar}$ faceted catalyst results in the growth of CNFs with specific herringbone-type structure, in which graphene sheets are packed perpendicularly to the longitudinal fibers axis, and suggests quasi same diffusion/precipitation of carbon at base/slanting planes of catalyst (Fig. 9A). A similar structure was observed exclusively for the small Ni particles $(\sim 15 \mathrm{~nm})$, as a secondary product of acetylene decomposition. ${ }^{5}$

Despite highly faceted catalyst, a decomposition of ethane on iron nitride results in "hollow" bamboolike CNFs/CNTs structures with arches, and conical or parallel to longitudinal axis orientation of external walls (Fig. 9 B). (The impact of catalyst diameter on the formation of "hollow" structures can be here omitted, as curiously, a diameter of ammonia treated particles is slightly lower (20-35 nm) than the one of hydrogen treated particles $(35-45 \mathrm{~nm}))$. According to the literature, the "hollow" structure suggests that carbon diffusion hardly happens in the bulk (or basal plane). This indicates the contribution of $\mathrm{FeN}_{\mathrm{x}}$ species, where the introduction of nitrogen causes the increase of bulk density. ${ }^{3}$

We suggest also that the observed above high activity of the $\mathrm{FeN}_{\mathrm{x}}$ phase in the etching of graphitized carbon may be considered in the growth of doped carbon nanostructures. Depending on the applied conditions during the growth of $\mathrm{N}$-doped carbon nanostructures, such etching of the precipitated carbon layers might occur. 

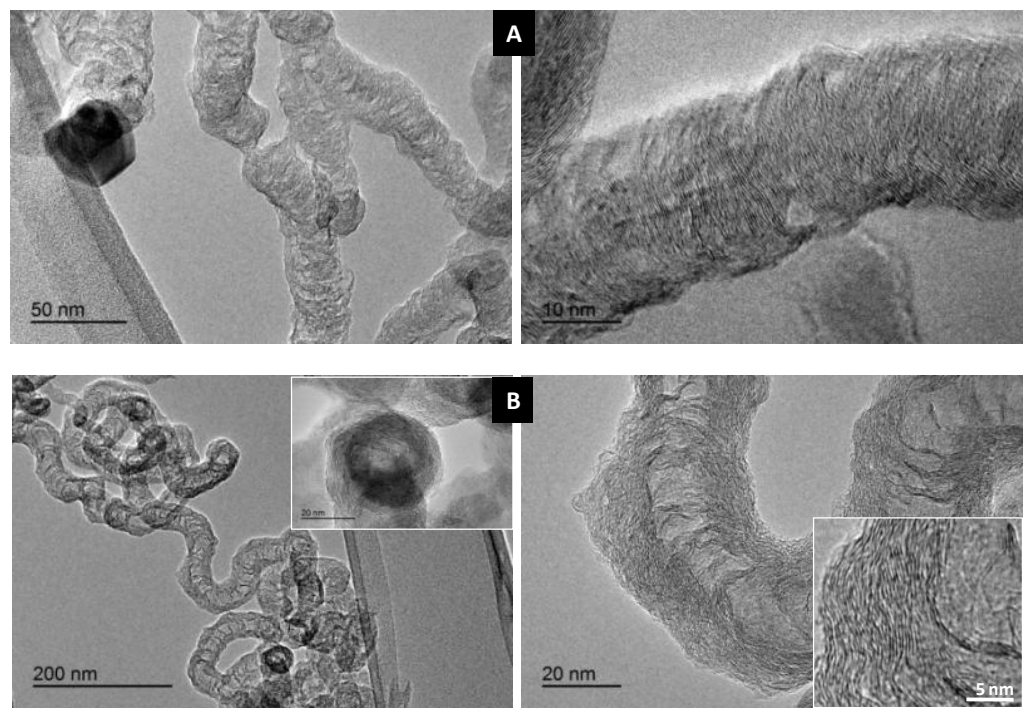

Figure 9. (A) Herringbone-type CNFs grown on $\mathrm{H}_{2} /$ Ar faceted catalyst. (B) "Hollow" bamboo-like CNFs/CNTs grown on $\mathrm{NH}_{3} / \mathrm{Ar}$ faceted catalyst.

The conical shape of the walls, including external ones, in bamboo-likes CNFs depicts faster precipitation of carbon at the slanting planes of catalyst compare to the herringbond CNFs originated from $\mathrm{H}_{2} / \mathrm{Ar}$ treated particles. This indicates that the sharp edges faceted catalyst acts. ${ }^{5}$

In some bamboo-likes filaments, however, the orientation of the external walls is parallel to a longitudinal axis, which uncovers rather CNTs morphology and suggests different faceting /nitrogen content in the bulk and at the surface of catalyst (the parallel external walls were found also for triangular aches $\mathrm{CNTs}^{12}$ ). We have assigned this carbon structure to the punctually observed spherical like particles with highly facet $\mathrm{FeN}_{\mathrm{x}}$ core, detected even by standard TEM analysis (Fig.10). For this reason we call them bamboo-like CNTs and not CNFs.
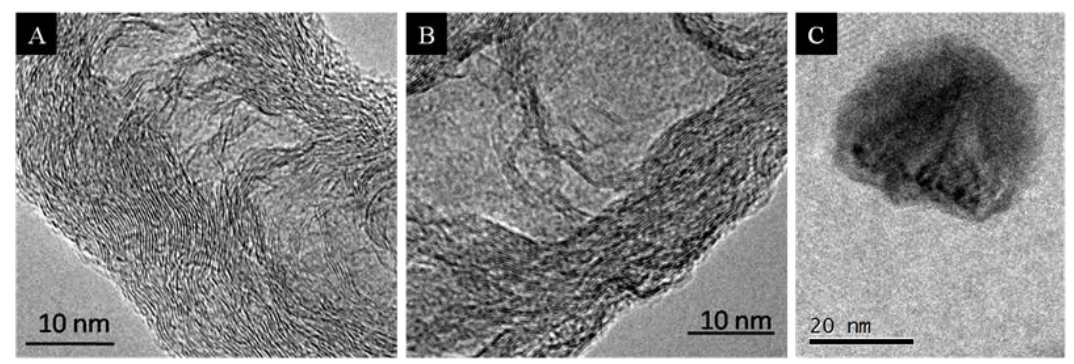

Figure 10. TEM micrographs of hollow bamboo-like CNFs (A) and CNTs (B) and related to the CNTs catalyst particle.

To complete the investigation on the catalyst - grown nanofilaments structure relation, a decomposition of ethane is performed additionally on the reduced at $400^{\circ} \mathrm{C}$ (not faceted), spherical iron catalyst. Adequately, it results in the formation of typical hollow carbon nanotube structure (SI).

\section{Experimental}

Ammonia treatment of $\mathrm{Fe}_{3} \mathrm{O}_{4} / \mathrm{FLG}$ was performed in a tubular quartz reactor at $800^{\circ} \mathrm{C}$ for $2 \mathrm{~h}$, using the gas mixture of $\mathrm{NH}_{3}: \mathrm{Ar}(50: 50 \mathrm{cc})$. The cooling step was performed under $\mathrm{NH}_{3}: \mathrm{Ar}(50: 50 \mathrm{cc})$ mixture or pure Ar. 
The synthesis of carbon nanostructures (CNFs, bamboo-like CNFs/CNTs and CNTs) were performed under ethane decomposition at $800^{\circ} \mathrm{C}$ for $1 \mathrm{~h}$ in the presence of $\mathrm{H}_{2} / \mathrm{Ar}$ with the ethane: $\mathrm{H}_{2}$ : $\mathrm{Ar}$ ratio of 100:10:100 cc, respectively. The synthesis of bamboo-like CNFs and CNFs were preluded by faceting of FLG- supported $\mathrm{Fe}_{3} \mathrm{O}_{4}$ particles with $\mathrm{NH}_{3} / \mathrm{Ar}$ (above) and $\mathrm{H}_{2} / \mathrm{Ar}$ (same procedure) respectively. The synthesis of CNTs was preluded by $2 \mathrm{~h}$ reduction step with $\mathrm{H}_{2} / \mathrm{Ar}, 50: 50 \mathrm{cc}$ at $400^{\circ} \mathrm{C}$.

For the TEM analyses, a drop of suspension containing the FLG $\left(\mathrm{Al}_{2} \mathrm{O}_{3}\right)$ supported iron-based NPs nanoaggregates was deposited on a TEM grid covered by a holey carbon membrane. The energy filtered images of the tilt series were obtained using a JEOL 2100F (FEG) TEM/STEM electron microscope operating at $200 \mathrm{kV}$, equipped with a TRIDIEM post-column imaging filter of the Gatan Company. The images acquired on a $2048 * 2048$ pixel cooled CCD detector were hardware-binned to $512 * 512$ pixels. The three-window method was used to acquire EFTEM images with a monotonic dependence of the chemical signal as a function of concentration.

\section{Conclusions}

The new important aspects linked up with the conditioning of iron based catalyst by nitridation/faceting; and its reactivity with carbon are reported:

- A decomposition of ammonia with the formed active $\mathrm{FeN}_{\mathrm{x}}$ catalyst may be a way to etches graphene with required nanostructuration of graphene tranches and potential decoration of etches by nitrogen;

- An observed bulk diffusion of nitrogen into the iron-based particles and interaction of the particles with FLG condition the particles' faceting and stability;

- The punctually observed facet triangle $\mathrm{FeN}_{\mathrm{x}}$ catalyst explains a triangularization of arches in highly CNTs highly doped by N;

- The influence of the shape/nitridation on the variable carbon layers orientation and carbon diffusion/precipitation in the grown carbon nanofilaments is presented for the first time within a given catalytic system.

- The $\mathrm{FeN}_{\mathrm{x}}$ morphological investigations contribute to the knowledge on the catalyst for ammonia decomposition, an important reaction in energy production.

\section{Notes and references}

$\dagger \quad$ Electronic Supplementary Information (ESI) available: Additional data dealing with the crystallographic structure and reorganization of $\mathrm{FeN}_{\mathrm{x}}$ particles (XRD, HR-TEM, TEM) complementary description of carbon nanotubes growth.

See DOI: 10.1039/b000000x/

\section{Acknowledgment}

The authors would like to acknowledge the project FreeCats (NMP3-SL-2012-280658) for financial support. 
1. Z.X. Yu, D. Chen, B. Totda, A. Holmen, J.Phys.Chem. B, 2005, 109, 6096.

2. Z. X.Yu, D. Chen, M. Rønning, B. Totdal, T. Vralstad, E. Ochoa-Fernandez, A. Holmen, Appl. Catal. A, 2008, 338, 147.

3. J.P. Tessonnier, D.S. Su, ChemSusChem, 2011, 4, 824.

4. I. Kvande, Z. Yu, T. Zhao, M. Rønning, A. Holmen, D. Chen, Chem.Sustainable Dev., 2006, 14, 583.

5. G.-B. Zheng, K. Kouda, H. Sano, Y. Uchiyama, Y.-F. Shi , H-J. Quan, Carbon, 2004, $42,635$.

6. I. Martin-Gullon, J. Vera, J.A. Conesa, J.L. González, C. Merino, Carbon, 2006, 44, 1572.

7. A. Rinaldi, J.-P. Tessonnier, M.E. Schuster, R. Blume, F. Girgsdies, Q. Zhang, T. Jacob, S.B. Abd Hamid, D.S. Su, R. Schlögl, R. Angew. Chem. Int. Ed., 2011, 50, 3313.

8. A.R. Harutyunyan, G.T. Chen, M. Paronyan, E.M. Pigos, O.A. Kuznetsov, K. Hewaparakrama, S.M. Kim, D. Zakharov, E.A. Stach, G.U. Sumanasekera, Science, 2009, 326,116.

9. T. Yamada, A. Maigne, M. Yudasaka, K. Mizuno, D.N. Futaba, M. Yumura, S. Iijima, K. Hata, Nano Lett., 2008, 8, 4288.

10. S. Hofmann, G. Csanyi, A.C. Ferrari, M.C. Payne, J. Robertson, J. Phys. Rev. Lett., 2005, 95, 036101 .

11. J.W. Jang, C.E. Lee, S.C. Lyu, T.J. Lee, C.J. Lee, App. Phys. Lett., 2004, 84, 2877.

12. I. Florea, O. Ersen, R. Arenal, D. Ihiawakrim, C. Messaoudi, K. Chizari, I. Janowska, C. PhamHuu, J. Am. Chem. Soc., 2012, 134 (23), 9672.

13. L.F. Mabena, S.S. Ray, S.D. Mhlanga, N.J. Coville, Appl Nanosci., 2011, 1, 67.

14. Y. Ma, L. Sun, W. Huang, L. Zhang, J. Zhao, Q. Fan, W. Huang, J. Phys. Chem. C, 2011, 115, 24592.

15. L. Feng, Y. Yan, Y. Chen, L. Wang, Energy Environ. Sci., 2011, 4, 1892.

16. K. Chizari, A. Deneuve, O. Ersen, I. Florea, Y. Liu, D. Edouard, I. Janowska, D. Begin, C. Pham-Huu, ChemSusChem, 2012, 5, 102.

17. Y. Shao, J Sui, G. Yin,Y. Gao, Appl Catal B Environ., 2008, 79, 89.

18. J. Liu, S. Webster, D.L. Carroll, J Phys Chem B, 2005, 109, 15769.

19. K.Y. Chun, H.S. Lee, C.J. Lee, Carbon, 2009, 47, 169.

20. Y. Ohtsuka, C. Xu, D. Kong, N. Tsubouchi, Fuel 2004, 83, 685.

21. W.P. Tong, N.R. Tao, Z.B. Wang, J. Lu, K. Lu, Science, 2003, 299, 686.

22. F.Charreteur, F. Jaouen, S. Ruggeri, J.-P. Dodelet, Electrochimica Acta, 2008, 53, 2925. 
23. H. Meng, N. Larouche, M. Lefevre, F. Jaouen, B. Stansfield, J.P. Dodelet, Electrochim. Acta, $2010, \mathbf{5 5}, 6450$.

24. U.I. Kramm, I. Herrmann-Geppert, P. Bogdanoff, S.J. Fiechter. Phys. Chem. C, 2011, 115, 23417.

25. F. Jaouen, F. Charreteur, J.-P. Dodelet, J. Electrochem. Soc., 2006, 153, 689; A.

26. U.I. Kramm, I. Herrmann-Geppert, P. Bogdanoff, S. Fiechter, J. Phys. Chem. C, 2011, 115, 23417.

27. F. Schüth, R. Palkovits, R. Schlögl, D.S. Su, Energy Environ. Sci., 2012, 5, 6278.

28. Zhang, M. Comotti, F. Schüth, R. Schlögl, D.S. Su, Chem. Commun., 2007, 1916.

29. X. Duan, G. Qian, X. Zhou, Z. Sui, D. Chen, W. Yuan, App. Catal. B: Environmental, 2011,101, 189.

30. C. Schliehe, J. Yuan, S. Glatzel, K. Siemensmeyer, K. Kiefer, C. Giordano, Chem. Mater., 2012, 24, 2716.

31. T. Ogi, A.B.D. Nandiyanto, Y. Kisakibaru, T. Iwaki, K. Nakamura, K. Okuyama, J. Appl. Phys., 2013, 113, 164301.

32. S.S. Datta, D.R. Strachan, S.M. Khamis, A.T.C. Johnson, Nano Lett., 2008, 8 (7), 1912.

33. L. Ci, Z. Xu, L. Wang, W. Gao, F. Ding, K.F. Kelly, B.I. Yakobson, P. M. Ajayan, Nano Res., 2008, 1, 116.

34. C.W.Keep, S. Terry, M. Wells, J. Catal., 1980, 66, 451-462.

35. W. Baaziz, L. Truong Phuoc, C.D. Viet, G. Melinte, I. Janowska, V. Papaefthimiou, O. Ersen, S. Zafeiratos, D. Begin, S. Begin-Colin, C. Pham-Huu, J.Mat.Chem. A, 2014, 2, 2690.

36. V. Papaefthimiou, I. Florea, W. Baaziz, I. Janowska, W. H. Doh, D. Begin, R. Blume, A. KnopGericke, O. Ersen, C. Pham-Huu, S. Zafeiratos, J. Phys. Chem. C, 2013, 117 (39), 20313.

37. J. Torres, C.C. Perry, S. J. Bransfield, D.H. Fairbrother, J. Phys.Chem.,B, 2003, 107, 5558.

38. C. Schliehe, J. Yuan, S. Glatzel, K. Siemensmeyer, K. Kiefer, C. Giordano, Chem. Mater., 2012, 24, 2716.

39. M. Jurčik-Rajman, S. Vepřek, Surf. Sci., 1987, 189/190, 221.

40. I. Janowska, M.-S. Moldovan, O. Ersen, H. Bulou, K. Chizari, M.-J. Ledoux, C. Pham Huu, C. Nano Res ., 2011, 4(5), 511.

41. M.-S. Moldovan, H. Bulou, Y.J. Dappe, I.Janowska, D. Bégin, C. Pham-Huu, O. Ersen, J. Phys. Chem. C, 2012, 116 (16), 9274. 